\title{
UNIVERSIDADE EMPRENDEDORA: FATORES QUE AFETAM A DECISÃO DE DOCENTES A CRIAR SPIN-OFFS ACADÊMICOS
}

Igor Augusto De Melo Dias ${ }^{1}$

Allan Claudius Queiroz Barbosa ${ }^{2}$

\footnotetext{
${ }^{1}$ Pontifícia Universidade Católica de Minas Gerais - PUC Minas

${ }^{2}$ Universidade Federal de Minas Gerais
} 


\section{UNIVERSIDADE EMPRENDEDORA: FATORES QUE AFETAM A DECISÃO DE DOCENTES A CRIAR SPIN-OFFS ACADÊMICOS}

Resumo: Este trabalho teve como objetivo identificar fatores que influenciaram na decisão de professores de uma Universidade Pública situada no estado de Minas Gerais a optaram por criar spin-off com o objetivo de explorar as tecnologias resultantes das pesquisas desenvolvidas por eles dentro da instituição. Com base na análise de documentos foi possível identificar 16 casos de empresas criadas, com participação de professores, e que exploravam propriedade intelectual da universidade e que tinham a participação de professores como um dos sócios. Por meio de entrevista semi-estruturadas com 9 desses professores foi possível identificar a carência de programas que fomentem o empreendedorismo acadêmico. A principal motivação para a criação dos spin-offs foi a difusão da tecnologia e os possíveis impactos sociais e econômicos gerados pela pesquisa. Os professores continuaram com a sua missão na Universidade, sem nenhum prejuízo para as atividades acadêmicas e as experiências como empreendedores contribuíram na formação dos discentes.

Palavras-chave: empreendedorismo. spin-off acadêmico. universidade empreendedora. Transferência Tecnológica

\section{$1 \quad$ Introdução}

Dentro de uma economia baseada no conhecimento, as instituições de ensino que possuem vocação para pesquisa, exercem um papel central no sistema de inovação. Atualmente, as Universidades estão vivendo a sua segunda revolução, na qual passam a incorporar, além das atividades de ensino e pesquisa, também aquelas capazes de gerar impacto social e econômico, que são definidas como terceira missão. (ETZKOWITZ et al., 2000)

A mudança de uma perspectiva centrada apenas em pesquisas básicas para o um modelo empresarial fez com que diversas Universidades dos Estados Unidos e de outros países concentrassem atenção no potencial de geração de receitas oriundos dos processos de transferência tecnológica. Da mesma forma, elaboradores de políticas públicas, em várias partes do mundo, compreenderam que a transferência tecnológica exerce um papel relevante no desenvolvimento econômico tanto no nível nacional, quanto no nível regional(GARNSEY; STAM; HEFFERNAN, 2006; PHAN; SIEGEL, 2006).

Esta temática se insere no contexto de aumento da competitividade econômica mundial. Isso obrigou que determinadas regiões repensassem suas estratégias de desenvolvimento econômico. Tendo em vista que um dos pilares para vantagem competitiva é o conhecimento, elaboradores de políticas públicas estão desenvolvendo estratégias que visam apoiar o surgimento de empresas de base tecnológica oriundas de universidades (O'SHEA et al., 2007).

O spin-off acadêmico é um tipo de empresa de base tecnológica, criada com objetivo de explorar a propriedade intelectual desenvolvida dentro das Universidades. Elas podem, ou não, contar com a participação de pesquisadores e possuem grande potencial para gerar postos 
de trabalhos para profissionais com formação de ponta e contribuem para o desenvolvimento econômico regional. Como se trata de um dos caminhos viáveis para fazer transferência de propriedade intelectual entre Universidade empresa, as pesquisa sobre o tema despertam interesse tanto do meio acadêmico, quanto de elaboradores de políticas públicas (SHANE, S. A., 2004).

No Brasil, a partir da promulgação da Lei no 10.973/2004 e do novo marco legal da inovação, também conhecido como Código de Ciência, Tecnologia e Inovação (13.243/2016),observa-se um fortalecimento de um ambiente favorável à cooperação para que possa ocorrer pesquisa e inovação dentro do país (RAUEN, 2016). Além disso, mudanças na cultura de diversos departamentos dentro das Universidades também despertaram interesse de acadêmicos em empreender com tecnologias resultantes de suas pesquisas.

Tendo em vista a relevância do tema, o objetivo deste trabalho é identificar quais fatores influenciaram docentes/pesquisadores, vinculados à Universidade Federal de Minas Gerais (UFMG), a criar spin-offs, com o objetivo de explorar resultados das pesquisas acadêmicas. Além disso, busca-se compreender como são geridos conflitos de tempo, causados pelas demandas entre as atividades de pesquisa, ensino e empresarial. Por fim, serão investigados os principais entraves e facilitadores encontrados no processo de empreender no meio acadêmico.

\section{Universidade Empreendedora}

Existe uma tendência de que a comercialização da propriedade intelectual desenvolvida dentro das universidades se torne um objetivo institucional em diversas instituições do mundo. Algumas evidências empíricas mostram que as instituições acadêmicas estão adotando um formato comum no que diz respeito às atividades empresariais. Essas transformações estão em conformidade com a "terceira missão" das universidades, que se refere ao desenvolvimento econômico (ETZKOWITZ et al., 2000).

De acordo com Etzkowitz et al. (1998), as universidades passaram pela sua primeira revolução quando a função pesquisa foi adicionada ao ensino. Atualmente está em curso a segunda revolução, que consiste em incorporar o desenvolvimento econômico e social em sua missão. Essa nova concepção contribui de forma direta para o surgimento de novas tecnologias (ETZKOWITZ et al. 2000).

Tendo como base o conceito de economia do aprendizado, Lundvall (2002) sugere que as mudanças ocorridas dentro das universidades são resultantes e acompanham novas dinâmicas das esferas econômicas. Isso implica em compreender a universidade como um ator envolvido no processo de direcionamento do mercado. O conhecimento produzido dentro deste novo contexto é capaz de interferir no nível de internacionalização.

O conceito de universidade empreendedora contempla uma estrutura acadêmica alinhada com o desenvolvimento econômico, além da realização de pesquisa e ensino. Tratase de um processo que surge como resposta para o aumento da importância do conhecimento nos sistemas de inovação nacional e regional e que reconhece na universidade a capacidade de criar e transferir conhecimento e tecnologia (ETZKOWITZ et al. 2000).

De acordo com Etzkowitz et al. (2000),essas mudanças dentro das universidades devem ser interpretadas com base no modelo da hélice tripla, que postula que a interação 
entre universidade-governo e indústria é essencial em uma sociedade baseada no conhecimento.

Dentro deste modelo a indústria assume o papel de produtor, enquanto o governo é o garantidor das relações estáveis e a universidade é a fonte de novos conhecimentos e tecnologias. Deste modo, nota-se o crescimento da relevância da universidade para o desenvolvimento econômico e social. Em momento anterior havia apenas a dicotomia EstadoMercado (ETZKOWITZ, 2003).

$\mathrm{Na}$ hélice tripla, a universidade passa e ser um elemento central no sistema de inovação, tendo em vista que ela é capaz de fornecer não apenas capital humano, mas também fornecer o ambiente adequado para o surgimento de novas empresas. A esfera pública, privada e acadêmica está trabalhando de forma cada vez mais conectadas nos diversos estágios de inovação e dos processos de elaboração de políticas para a área industrial (ETZKOWITZet al., 2000).

Um ponto de partida importante para entender as transformações que aconteceram dentro das universidades ocorreu em virtude de uma importante mudança na legislação Norte Americana, que contribuiu para o aumento do pedido de concessão de patentes realizados nas universidades dos Estados Unidos. A BayDoleActpassou a encorajar as instituições de pesquisa a criar seus escritórios de transferências de tecnologias com o objetivo de levar para o mercado as invenções patenteadas (COLYVAS et al., 2002).

De acordo com Colyvas et al. (2002), o aumento do número de patentes registrados por universidades americanas teve um crescimento exponencial após a década de 1980, não só com relação ao número de patentes registradas, mas também no que diz respeito à geração de receita decorrente do processo de transferência tecnológica.

Nos dias de hoje, há um consenso de que governantes, universidades e a indústria devem ser capazes de promover a criação de empresas de base tecnológica, tendo em vista que a própria sociedade demanda das universidades um papel mais ativo e comprometido com questões relacionadas ao desenvolvimento e crescimento econômico (DEL PALACIO AGUIRRE et al., 2006).

A criação de spin-offs, que surgem com o objetivo de explorar as tecnologias desenvolvidas dentro das universidades, é a forma mais efetiva de transferir tecnologia. Entretanto, é necessário destacar que se trata de um processo complexo, que não é linear nem sistemático. Ao contrário disso, é um processo marcado por incertezas, no qual o sucesso depende de muitas variáveis (DEL PALACIO AGUIRRE et al., 2006).

As discussões sobre os empreendedorismos deixam claro que o empreendedor é capaz de identificar uma oportunidade (SHANE e VENTKATARAMN, 2000) ou criar uma oportunidade (ALVAREZ e BARNEY, 2006). Além disso, o empreendedor é tratado como alguém que leva uma inovação para o mercado, a qual é capaz de gerar desequilíbrio por meio da destruição criativa (SHUMPETER, 1934).

Uma vez que as universidades são lócus da pesquisa e assumiram, como terceira missão, gerar impacto econômico e social, torna-se essencial entender características institucionais que influenciam nas decisões dos acadêmicos de explorar as oportunidades encontradas ou, até mesmo, identificarem novas oportunidades por meio da sua pesquisa. 
A seguir serão apresentados os principais aspectos conceituais de spin-off acadêmico, que é um dos caminhos existentes para que pesquisadores e professores possam levar suas pesquisas para o mercado.

\section{Spin-off Acadêmico}

A criação de empresas, a partir das pesquisas desenvolvidas dentro da universidade, não é um fenômeno novo. De acordo com ETZKOWITZ (1998) existem registros no século XVII que mostram que a indústria farmacêutica na Alemanha surgiu com base em pesquisas acadêmicas. DRUILHE; GARNSEY (2004) destacam o caso da Cambridge Scientific Instruments, que foi uma empresa fundada por Horace Darwin,em 1881, decorrente das pesquisas realizadas na Universidade de Cambridge.

Os spin-offs baseados em pesquisas acadêmicas é um fenômeno que atrai a atenção de acadêmicos e formuladores de políticas públicas, pois estes tipos de empreendimentos estimulam a economia nacional e regional. Contudo, existe um processo com inúmeros obstáculos para se estabelecer uma empresa desse tipo no mercado e gerar retornos financeiros sustentáveis (MUSTAR et al., 2006).

Não há um consenso de que as universidades devem estar envolvidas em atividades comerciais. O crescimento econômico de geração de novos empregos são os principais argumentos utilizados por aqueles que defendem o engajamento das universidades na criação de empresas baseadas no conhecimento científico. Dessa forma, novas empresas tecnológicas são exemplos de investimentos públicos nas universidades que podem gerar impactos nas atividades econômicas, tanto no âmbito regional quanto nacional (RASMUSSEN e WRIGHT, 2015).

Do outro lado, há críticas que devem ser levadas em conta com relação à criação de spin-off. A principal delas é o conflito de interesses e o desvirtuamento do papel da universidade como produtora de conhecimento independente. Eventualmente, pesquisadores podem optar em ter mais atenção ao aspecto econômico da pesquisa do que do próprio processo de formação dos alunos (RASMUSSEN e WRIGHT, 2015).

Lockett e Wright (2005, p.1044) definem os spin-offs como "novos empreendimentos que dependem de licenciamento ou da cessão da propriedade intelectual da instituição para iniciar". Já Rasmussen e Wright (2015) definem os spin-offs universitários como um tipo de empresa que inicia suas atividades dentro do ambiente acadêmico e utiliza tecnologias baseadas nas pesquisas realizadas pela universidades.

Já para Shane (2004, p.4) spin-off acadêmico pode ser definido como"uma nova empresa fundada para explorar parte da propriedade intelectual criada em instituições acadêmicas". É importante destacar que o que define um spin-off não é o fato dele ser composto por membros da universidade, e sim pelo fato de a empresa surgir com o propósito de comercializar propriedade intelectual desenvolvida dentro de instituições acadêmicas. Portanto, uma empresa criada com o objetivo de explorar uma tecnologia desenvolvida pela Universidade que não possua professores, pesquisadores ou alunos da instituição também são considerados spin-off acadêmicos (SHANE, 2004).

Dentre os elementos que compõem os conceitos acima apresentados, é necessário chamar atenção para o fato de que os spin-offs são empresas novas. Isso significa que elas não 
são consideradas uma extensão e nem uma subsidiária da universidade. O spin-off possui o status legal da instituição que deu origem a ele (PIRNAY, 2003).

Também deve-se ter atenção ao fato de que os spin-offs podem explorar inovações tecnológicas ou patenteadas, mas também podem surgir para explorar o know-how do pesquisador, que foi acumulado durante o tempo que eles /elas desenvolveram determinadas atividades acadêmicas (PIRNAY, 2003).

As universidades podem oferecer suporte de diversas formas, como: incubadoras, competição de planos de negócios ou modelos de negócios, fundos de investimentos que capital parcial ou completo da própria universidade. Além disso, de forma indireta é possível citar os procedimentos normas necessárias para explorar as tecnologias universitárias (FINI, 2008).

Fatores como excelência em pesquisa, em diversos campos práticos, com viés interdisciplinar, fortalecimento do relacionamento entre governo, indústria e academia, estrutura organizacional dedicada ao processo de transferência tecnológica, treinamento de empreendedores acadêmicos potenciais, aspectos relacionados à missão, crenças e cultura organizacional são alguns pontos que refletem o impacto positivo gerado pelo MIT (O`SHEA et al., 2007).

Os achados de Finiet al. (2008) sinalizam que a disponibilidade de recursos para pesquisa, com potencial para exploração comercial e suporte por parte das universidades, são alguns dos fatores que incentivam a criação os spin-offs.

O escritório de transferência de propriedade intelectual deve desempenhar um papel importante, tendo em vista que ele deve ser capaz de avaliar o potencial comercial de uma tecnologia, que surgiu em um ambiente tradicionalmente não comercial, como é caso das universidades. Isso significa que a disponibilidade de pessoas nos ETPI's tendem a impactar diretamente a criação de spin-off (LOCKETT e WRIGHT, 2005).

Uma política adequada para o surgimento de spin-off acadêmico deve contar com mecanismos que permitam identificar, dentro dos centros de pesquisa, as idéias com maior potencial econômico, de modo que seja possível proteger as tecnologias desenvolvidas por meio de patenteamento (PIRNAY et al.,2003).

A delimitação do conceito de spin-off e o seu processo de criação ajudam a compreender o fenômeno estudado de forma ampla. A seguir serão detalhadas as principais características e motivações de empreendedores que identificam e exploram oportunidades por meio da criação de uma nova empresa.

No começo da década de 1970, diversos pesquisadores que buscavam capitalizar pesquisas na área das ciências da vida, sofreram a desaprovação da comunidade científica. Contudo, nos dias de hoje, é comum que empreendedores que fazem a comercialização das suas descobertas, seja ela por meio da criação de um spin-off ou pelo processo de licenciamento, não tenham mais esse tipo de preocupação (STUART e DING, 2006).

Muitos dos pesquisadores que tem interesse em empreender por meio de um spin-off esbarram na ausência de habilidades comerciais, que são essenciais para fazer com que as tecnologias consigam cheguem até o mercado. Além disso, as atividades de pesquisa com foco comercial tendem a gerar conflitos de interesses entre as diversas partes interessadas, 
como empreendedores acadêmicos, universidades, equipe e investidores (CLARYSSE et al., 2005; MUSTAR et al., 2006).

Dessa forma as Universidades direcionam a forma com os indivíduos irão atuar, sendo responsáveis por promover de forma explicita e implícita um conjunto de normas e valores. O treinamento profissional é estabelece a forma de difundir novas idéias e práticas. Por isso, os indivíduos que se formaram em instituições que estão fortemente envolvidas com atividades de transferência tecnológica tem uma probabilidade maior de adotar essas práticas em suas carreiras e criar spin-off (BERCOVITZ e FELDMAN, 2008).

A pesquisa realizada por Stuart e Ding (2006) teve como objetivo compreender o impacto de quatro determinantes no processo de transição individual dos membros do corpo docente da pesquisa básica para ciência comercial: socialização na graduação, influência entre pares, agrupamento espacial de transição e acesso diferencial aos recursos sociais, que facilitam o comportamento empresarial.

Para Stuart e Ding (2006), o contexto do trabalho influencia a probabilidade do cientista se tornar empreendedor. A proximidade física de adotantes da ciência comercial influenciam outros cientistas na adoção desta prática. Além disso, o relacionamento entre pares também demonstra ser um forte elemento que impacta na decisão de pesquisadores a se envolverem nas atividades de transferência tecnológica. Ou seja, a frequente interação social é capaz de moldar o comportamento dos pesquisadores(BERCOVITZ e FELDMAN, 2008).

A reputação dos pesquisadores e a excelência científica, que normalmente estão vinculados a universidades renomadas, são fatores facilitadores que facilitam a criação de spin-off. Existe uma probabilidade maior que este tipo de pesquisador consiga obter recursos necessários para o estabelecimento da nova tecnologia, uma vez que a qualidade e a reputação contribuem para uma redução do problema da assimetria da informação (AMBOS, 2008; CLARYSSE, TARTARI e SALTER DI GREGÒRIO e SHANE, 2003). Os melhores cientistas são aqueles que possuem maior possibilidade de empreender (FINI et al., 2008).

Por fim, são apresentados os impactos das políticas da Universidade na formação de Spin-off. De acordo com Di Gregorio e Shane (2003) é possível identificar quatro pontos relevantes. O primeiro deles se refere à forma como a distribuição dos royalties são realizados, uma vez que isso pode propiciar mais interesse dos inventores em levar as tecnologias por eles desenvolvidas para o mercado. A tendência é que os inventores tenham um ganho menor com a criação de uma empresa do que com processo de licenciamento com empresas já estabelecidas.

No caso Brasileiro, é importante destacar que a lei 13.243 de 2016 define no inciso I, do parágrafo único do art. $1^{\circ}$ "a promoção de atividades científicas e tecnológicas como estratégicas para o desenvolvimento econômico social”.Além disso.A referida lei assegura recursos financeiros, econômicos e humamos com o objetivo de garantir a inovação.

$\mathrm{Na}$ figura a seguir, as setas sinalizam que os governos contribuem com políticas e fundos de financiamento para a inovação, bem como com ajustes na legislação que permitam tornar o processo de desenvolvimento de tecnologias com potencial comercial. Por outro lado, espera-se crescimento econômico, por meio da criação de spin-offs que atuam com inovações de ponta. Dessa forma, evidencia-se o paradigma Shumpeteriano do empreendedor como mola propulsora da economia, apoiado pelo Estado, conforme Mazucato (2014). 
As influências departamentais exercidas sobre os pesquisadores também estão em evidência na literatura (STUART e DING, 2006, ClARYSSEet al.,2011; BERCOVITZ e FELDMAN, 2002). As normas sociais de cada departamento são capazes de gerar impacto na decisão do empreendedor de explorar a oportunidade comercial encontrada na sua pesquisa. Contudo, a partir do momento que um spin-off e gerado dentro de um departamento, há uma abertura para que outros possam surgir, por isso, o fluxo também é de mão dupla.

FIGURA 1-Fatores que afetam decisões dos pesquisadores/professores para criar Spinoff.Fonte: elaborado pelo autor.

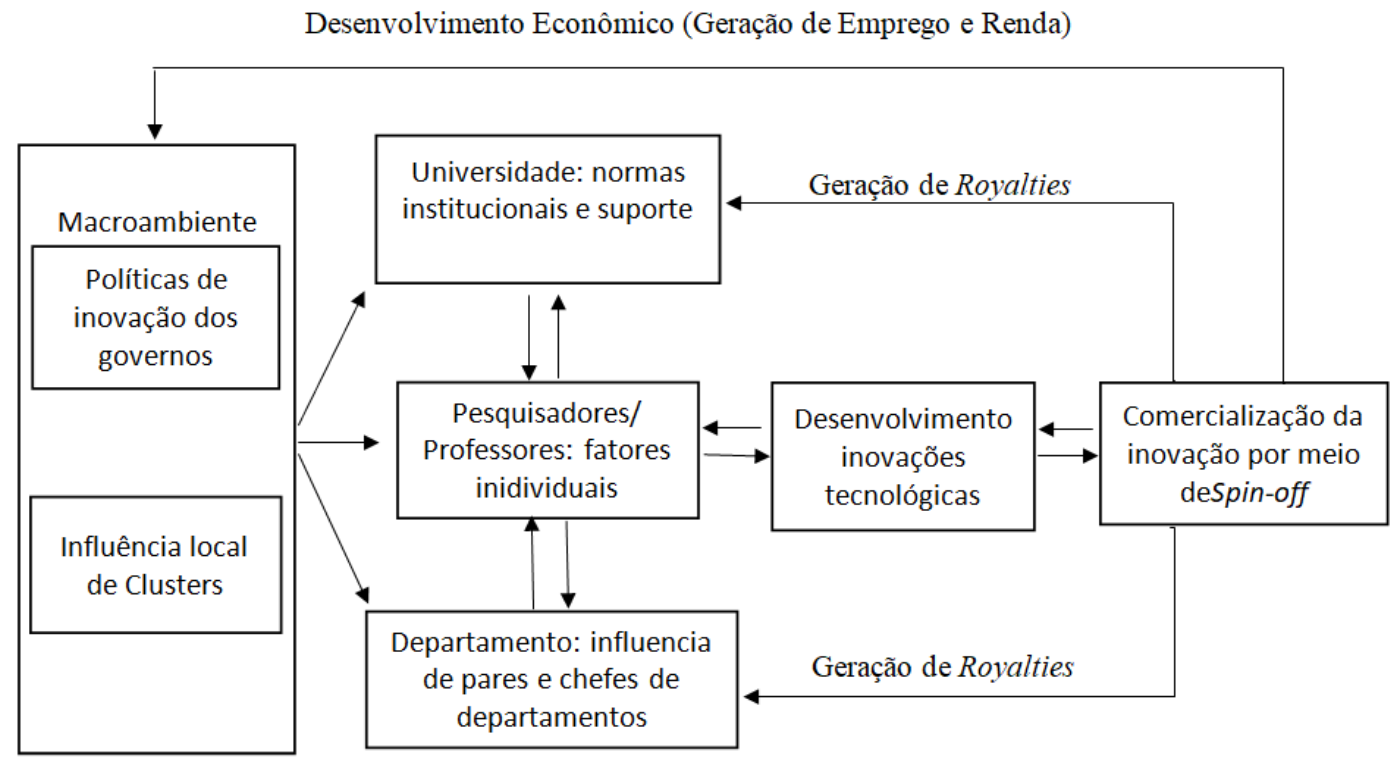

Fonte: Elaborado pelo Autor

Já as Universidades são capazes de influenciar o surgimento de novas tecnologias e criação de spin-off por meio dos seus escritórios de transferências tecnológicas (COLYVAS et $a l ., 2002)$, por meio da criação de incubadoras e fundos de investimentos, entre outros ((DI GREGÒRIO e SHANE, 2003; RASMUSSEN e WRIGHT, 2015).

Os fatores individuais, contudo, são os que chamam mais atenção. Tendo em vista que o pesquisador dever atuar como empreendedor, sendo capaz de identificar a oportunidade (SHANE e VENKATMARAN, 2000) ou, na maioria das vezes, criar uma oportunidade e explorá-la com base nos resultados de pesquisa (ALVAREZ e BARNEY, 2006). Além disso, no nível individual, é possível identificar influenciado nível de publicações (BERCOVITZ e FELDMAN, 2002), o ciclo de vida do acadêmico (SHANE, 2004), a melhoria do do status acadêmico (FINI et al.,2008).

A seguir são tratados os principais aspectos metodológicos desta pesquisa, que tem por objetivo identificar fatores que levaram os pesquisadores/professores da Univerisdade Federal de Minas Gerais a levar tecnologias resultantes, por meio de processo de pesquisa, para o mercado,através da criação de spin-offs.

\section{Metodologia}


Para a concretização desta pesquisa, optou-se por uma abordagem analítica do tipo qualitativa descritiva, seguindo a proposta de Creswell (2007) e por uma metodologia de estudo de caso, conforme Yin (2005). O propósito central foi, a partir dos casos estudados, entender como as trajetórias de carreira dos docentes e aspectos do ambiente universitário influenciaram na decisão de realizar pesquisas com foco comercial levando à criação de spinoff.

O levantamento de dados por meio de documentos contemplou portarias, legislação, informações contidas no site da UFMG e de órgãos da Universidade (tais como Coordenação de Transferência Tecnológica), análise do currículo lattes dos pesquisadores, acordos de licenciamento firmados entre docentes e Universidade Federal de Minas Gerais, Contratos Sociais de empresas que firmaram contrato de licenciamento com a UFMG e atas de reuniões.

A entrevista semi-estruturada foi o instrumento escolhido pela levantar dados primários. Por meio destra instrumento, os entrevistados discorreram sobre o tema sem se prender à questão a ele apresentada. Esse tipo de entrevista difere muito pouco da entrevista aberta, tendo em vista que o processo de coleta de dados sempre terá um objetivo previamente definido (MNAYO, 2008).

Após a coleta de dados, foi registrada a transcrição das fitas. De acordo com Bardin (2011) e Gibbs (2009), esse processo é imprescindível para a realização das análises. Após a preparação do material, a avaliação das entrevistas foi realizada por meio da análise qualitativa de conteúdo, que é um método que tem como uma das suas características essenciais a utilização de categorias normalmente obtidas por meio de modelos teóricos(BARDIN, 2011; FLICK, 2004; GIBBS, 2009; MINAYO, 2008).

O desenvolvimento das categorias, apresentado no quadro 1 foi realizado com base no roteiro das entrevistas semi-estruturadas, de modo que o conteúdo coletado pudesse ser analisado. As categorias, criadas com base no referencial teórico, buscam o melhor entendimento sobre quais fatores influenciaram para que o acadêmico começasse a fazer pesquisa com foco comercial e quais foram os principais entraves e facilidades encontrados para a criação dos spin-off.

QUADRO 1- Perguntas, categorias e tópicos de análise das entrevistas.

\begin{tabular}{l|l|l}
\hline \hline Categorias & Subcategorias & \multicolumn{1}{|c}{ Dimensões } \\
\hline \multirow{2}{*}{} & Realização profissional & $\begin{array}{l}\text { Identificação da carreira como processo de realização } \\
\text { profissional, de modo a satisfazer necessidades intrínsecas. }\end{array}$ \\
\cline { 2 - 4 } & $\begin{array}{l}\text { Conjunto de atividades } \\
\text { realizadas }\end{array}$ & $\begin{array}{l}\text { Associação da carreira profissional com o conjunto de atividades } \\
\text { realizadas para cumprir determinados objetivos. }\end{array}$ \\
\cline { 2 - 4 } & Posições de trabalho & $\begin{array}{l}\text { Carreira vista como processo burocrático, no qual você ocupa } \\
\text { diversos cargos até chegar ao nível mais alto, que é o de } \\
\text { professor titular. }\end{array}$ \\
\hline \hline
\end{tabular}




\begin{tabular}{|c|c|c|c|}
\hline 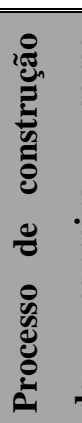 & 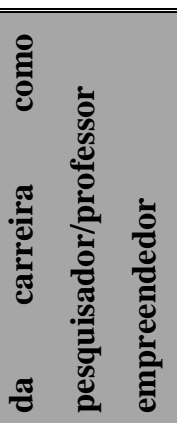 & $\begin{array}{l}\text { Ciclo de Vida da } \\
\text { Carreira. }\end{array}$ & $\begin{array}{l}\text { Identifica o estágio da carreira que o pesquisador/professor } \\
\text { estava quando optou por fazer pesquisa aplicada e, em seguida, } \\
\text { tentar comercializá-la por meio da criação de spin-off acadêmico. }\end{array}$ \\
\hline 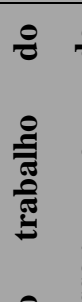 & ¿ & $\begin{array}{l}\text { Pontos } \\
\text { convergência }\end{array}$ & $\begin{array}{l}\text { Identifica o ponto de interseção entre as duas carreiras, uma vez } \\
\text { que sem excelência em pesquisa é difícil alcançar bons } \\
\text { resultados como empreendedor acadêmico. }\end{array}$ \\
\hline בֶ, & 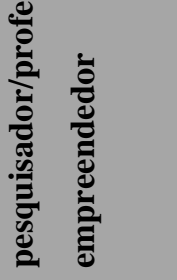 & Pontos de divergência & $\begin{array}{l}\text { Levantamento dos pontos que as duas carreiras se mostram } \\
\text { diferentes, muitas vezes relacionados a falta de conhecimento de } \\
\text { gestão em detrimento do excesso de conhecimento especializado } \\
\text { na área de atuação. }\end{array}$ \\
\hline 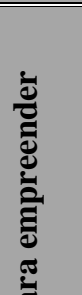 & & $\begin{array}{lr}\text { Identificação } & \text { ou } \\
\text { criação } & \text { da } \\
\text { oportunidade } & \text { e } \\
\text { capacidade } & \text { de } \\
\text { exploração. } & \end{array}$ & $\begin{array}{l}\text { Verificar se o empreendedor identificou uma oportunidade que } \\
\text { já existia, ou se criou nova oportunidade, e analisar o que o } \\
\text { motivou a explorá-la. }\end{array}$ \\
\hline 胥 & & $\begin{array}{l}\text { Impacto na carreira e } \\
\text { demais recompensas } \\
\text { intrínsecas } \quad \text { ou } \\
\text { extrínsecas. }\end{array}$ & $\begin{array}{l}\text { Identificar se a decisão de empreender é decorrente do desejo de } \\
\text { difundir a tecnologia, aumento do status acadêmico ou se a } \\
\text { decisão ocorre em decorrência de aspectos financeiros. }\end{array}$ \\
\hline
\end{tabular}




\begin{tabular}{|c|c|c|c|c|c|}
\hline 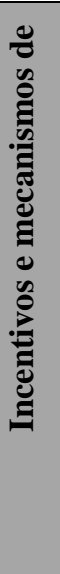 & 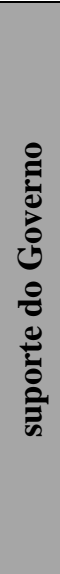 & 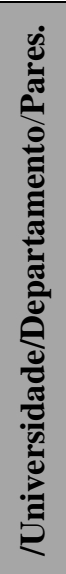 & & $\begin{array}{l}\text { Identificação do } \\
\text { suporte recebido. }\end{array}$ & $\begin{array}{l}\text { Levantamento de quais foram os principais incentivos que o } \\
\text { pesquisador/professor recebeu a partir do momento que ele } \\
\text { decidiu empreender, como treinamento, consultorias, troca de } \\
\text { experiência com colegas de departamento (pares). }\end{array}$ \\
\hline 悹 & $\stackrel{9}{\Xi}$ & 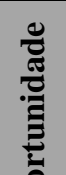 & हृ & $\begin{array}{l}\text { Conhecimento na área } \\
\text { de Gestão }\end{array}$ & $\begin{array}{l}\text { Verificar se os pesquisadores professores tinham as } \\
\text { competências de gestão para criar o spin-off. }\end{array}$ \\
\hline שٓ & $\approx$ & 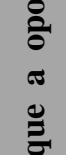 & 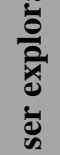 & Questões legais & $\begin{array}{l}\text { Identificar aspectos burocráticos que contribuíram, ou } \\
\text { atrapalharam, no momento de criação da empresa. }\end{array}$ \\
\hline 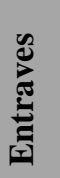 & 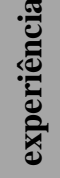 & 冚 & 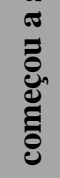 & Aspectos culturais & $\begin{array}{l}\text { Identificar se os aspectos culturais da Universidade contribuíram } \\
\text { ou atrapalharam o processo de criação dos spin-offs. }\end{array}$ \\
\hline 气ֶ气 & שֶ: & 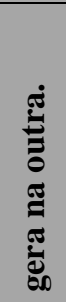 & & $\begin{array}{l}\text { Impactos que a carreira } \\
\text { empresarial gera na } \\
\text { acadêmica. }\end{array}$ & $\begin{array}{l}\text { Identificar quais são os impactos positivos e negativos que a } \\
\text { carreira empresarial gera na acadêmica. Bem como os impactos } \\
\text { positivos e negativos que a carreira acadêmica gera na } \\
\text { empresarial. }\end{array}$ \\
\hline
\end{tabular}

Fonte: Elaborado pelo autor

A escolha da UFMG como locos da pesquisa se deve a vocação que a instituição possui em fazer pesquisa aplicada. De acordo com o Boletim Mensal de Propriedade Intelectual, publicado pelo INPI em junho de 2017, a UFMG lidera o ranking de patentes de invenção, seguidas pela Universidade Estadual de Campinas (UNICAMP) e Universidade de São Paulo (USP). Além disso, Documentos fornecidos pela CTIT apresentam dados relevantes que sinalizam a tendência da instituição de geração de novas.tecnologias, tendo em vista que houve um crescimento de mais de $100 \%$ no número de pedidos de patentes entre os anos de 2007 de 2017.

O órgão responsável por disseminar a cultura do empreendedorismo, gerir e implementar a Política de Inovação da UFMG é a Coordenação da Transferência e Inovação Tecnológica (CTIT).A CTIT foi criada em 1997 e, desde então, promove ações que contribuem com o Sistema Nacional de Inovação, atuando na promoção da educação empreendedora, incentivando a criação de startups e spin-offs e fazendo a gestão da propriedade intelectual das tecnologias desenvolvidas dentro da UFMG. 
Com o objetivo de estimular o empreendedorismo, a UFMG possui a INOVA, que é uma incubadora de projetos de base tecnológica, o o Parque Tecnológico BH-Tec e também um fundo de investimentos de investimentos chamado FUNDEPAR Participações S.A que tem como fazer aportes financeiros em empresas emergentes de base tecnológica.

Dessa forma, é possível concluir que a UFMG possui um ambiente acadêmico favorável para a realização de pesquisas aplicadas e exploração de tecnologias por meio da criação de spin-off acadêmicos.

As informações iniciais para esta pesquisa foram levantadas em janeiro de 2017 junto ao departamento jurídico da CTIT. Nesta primeira etapa foram analisados todos os processos de transferência tecnológica realizados pela UFMG entre os anos de 2000 a 2016. Em um segundo momento identificou-se todos aqueles processos que a transferência foi realizada para empresas nascentes, em que um dos sócios era também professor da UFMG e figurava como um dos titulares da tecnologia patenteada.

Além disso, também foi levantada a data de abertura da empresa, a data de assinatura do contrato de transferência tecnológica e se a empresa conseguiu chegar na parte de comercialização da tecnologia, uma vez que este é um fato crítico de sucesso. Por fim, também foram mapeados os departamentos de origem do spin-off.

Sendo assim, o resultado foi a identificação de 16 spin-off que tiveram docentes como um dos fundadores da empresa. Com base neste resultado preliminar, foi possível identificar que eles estavam localizados em seis departamentos, conforme apresentado no quadro 2 a seguir:

Além disso, foi possível observar 4 casos de spin-off que não conseguiram explorar a tecnologias patenteadas e optaram por rescindir o contrato de licenciamento. Dessa forma, optou-se em priorizar contato com docentes que não apenas fundaram as empresas, mas que tentaram levar as tecnologias desenvolvidas para o mercado por meio de spin-off.

O levantamento de dados foi realizado considerando evidências primárias, cuja principal fonte foram7 entrevistas semi-estruturadas, com duração aproximada de 45 minutos, por um roteiro e realizadas com professores/pesquisadores que foram fundadores dos spin-offs identificados. As entrevistas foram realizadas pessoalmente, todas entre os meses de fevereiro de 2017 até março de 2018. Elas foram gravadas e transcritas, permitindo a recuperação dos dados para transposição das análises.

\section{Resultados}

De modo a facilitar a compreensão das descrições realizadas, optou-se por enumerar professores/pesquisadores. A seguir, segue o detalhamento das principais características deles, em relação à docência e ao spin-off (quadro3).

É importante destacar que todos os professores/pesquisadores identificados no levantamento documental realizado junto à CTIT foram contatados por e-mail. Quando não havia resposta, era realizado contato telefônico. Os motivos alegados para não realização da pesquisa foram: falta de tempo e receio de exposição.

Os resultados apresentados mostram uma forte consistência com o referencial teórico apresentado. Em um primeiro momento é importante destacar que, na visão dos próprios 
entrevistados, existe uma ideia de que o empreendedorismo acadêmico pode ser encaixado dentro da terceira missão da Universidade, conforme Etzkowittet al.(2000).

Quadro 3 - Características principais dos participantes

\begin{tabular}{|l|l|l|c|}
\hline \multicolumn{1}{|c|}{ Docente } & Ramo de atuação & \multicolumn{1}{c|}{ Situação atual } & $\begin{array}{l}\text { Tempo } \\
\text { spin-off }\end{array}$ \\
\hline Professor/pesquisador 1 & Química & $\begin{array}{l}\text { Docente/Não possui mais } \\
\text { participação na empresa. }\end{array}$ & anos \\
\hline Professor/pesquisador 2 & Farmácia & $\begin{array}{l}\text { Docente/Não possui mais } \\
\text { participação na empresa }\end{array}$ & anos \\
\hline Professor/pesquisador 3 & Biologia & $\begin{array}{l}\text { Docente aposentado/Presidente da } \\
\text { empresa. }\end{array}$ & anos \\
\hline Professor/pesquisador 4 & Engenharia Mecânica & $\begin{array}{l}\text { Docente aposentado/Presidente da } \\
\text { empresa }\end{array}$ & anos \\
\hline Professor/pesquisador 5 & Biologia & Docente/Conselho da Empresa. & ano \\
\hline Professor/pesquisador 6 & Biologia & Docente/Conselho da Empresa. & anos \\
\hline Professor/pesquisador7 & Química & Docente aposentado/Presidente da & anos \\
\hline
\end{tabular}

Fonte: Elaborado pelo autor.

Essa visão por parte de alguns professores/pesquisadores demonstra uma preocupação em realizar pesquisas aplicadas com potencial para alterar a realidades social e econômica do país. Sendo que em mais de uma fala havia interesse em gerar retornos com pesquisas também para própria universidade. De fato, a criação de um spin-off tende a gerar impactos na sua região de atuação, seja por meio de geração de empregos que demandam alto capital intelectual, seja por meio da movimentação da economia local (GARNSEY et al., 2006; PHAN; SIEGEL, 2006).

Outro aspecto que afetou os pesquisadores a explorarem as oportunidades identificadas é a falta de segurança, algumas falas demonstram preocupação com relação aos limites legais, no que diz respeito a dedicação de tempo ao spin-off, bem como a possibilidade de utilização dos laboratórios da própria instituição.

Os aspectos que motivaram os pesquisadores a empreenderem estão em conformidade com os achados de Hayter (2010), que identificou que a difusão e desenvolvimento das tecnologias como fator chave para a dedicação de pesquisadores na criação de empresas. Os entrevistados também sentiram a necessidade de afirmar que as tecnologias por eles desenvolvidas devem gerar impacto social em um primeiro lugar e colocaram a busca pelo lucro como fator secundário. 
O conceito de ciclo de vida acadêmica proposto por SHANE (2004) pode ser validado, tendo em vista que a amostra dos entrevistados confirma não só que eles estão no topo da carreira, uma vez que a totalidade da amostra já possível uma carreira estabilizada, sendo que boa parte dos entrevistados é professor titular. Isso sinaliza que eles desenvolveram capital humano antes de criar spin-off, que também foi atestado pelo impacto de publicações.

A qualidade da pesquisa dos pesquisadores/professores entrevistados parece ter sido um diferencial para que eles pudessem criar spin-off. Índices como impacto de publicações sinalizam o respeito que esses pesquisadores possuem dentro da comunidade acadêmica e até mesmo com futuros investidores (HAEUSSLER e COLYVAS, 2010).

Um aspecto relevante, pouco observado na fala dos entrevistados se refere a cultura de cada departamento. A literatura indica que os departamentos influenciam de forma direta na decisão de pesquisadores criarem suas empresas. Apena dois entrevistados mencionaram que a decisão de se envolver com atividades comerciais, como sãoos casos da criação de spinoff,demanda um aumento de produtividade, caso contrário, poderia haver questionamento por parte de pares, que não concordam com esse tipo de atividade dentro das universidades.

Alguns dos departamentos da UFMG tem maior potencial para pedido de patentes, bem como para criação de spin-off. No caso dos entrevistados, havia 1 da Engenharia, 1 da farmácia, 2 Química e 3 da Biologia. Não foi possível identificar de forma clara a influência departamental sobre os pesquisadores na decisão de empreendedor ou não. Entretanto algumas falas sinalizam que alguns pares com maior prestígio acadêmico geram influencias sobre os demais (CLARYSSE et al., 2011; STUART e DING, 2011).

$\mathrm{O}$ fato de alguns dos entrevistados terem vindo de Universidade de fora do Brasil onde a cultura para o empreendedorismo acadêmico é valorizada, impactou diretamente o resultado da pesquisa, e está em conformidade com os achados de Bercovitz e Feldman (2008). Este ponto destaca a necessidade de Universidades brasileiras criarem ambientes mais propícios para a criação deste tipo de empresa, o que pode ser realizado por meio de ajustes dentro de cada instituição

Os entrevistados mencionaram que identificaram uma demanda de mercado para as tecnologias desenvolvidas dentro do laboratório. De acordo com as falas, este foi um ponto essencial que os levou a optar por fundar um spin-off. Este ponto caminha em conformidade com o conceito proposto por Shane e Venktaraman (2000), que levam em consideração as características dos empreendedores, mas também levam em consideração as oportunidades.

Um ponto que chamou atenção na fala dos entrevistados é o fato de que eles mencionaram que a exploração comercial das suas tecnologias gerou impactos positivos para vida acadêmica. Contudo, ao serem questionados sobre os impactos que as atividades acadêmicas geraram nas atividades empresariais por eles desenvolvidas, a maioria mencionou existir apenas impactos positivos e não negativos, uma vez que a lei impede que eles tenham uma participação efetiva na empresa. Sendo assim eles participam apenas do conselho.

A resposta em si aponta para um problema relevante. Uma vez que a atividade empresarial só pode ser exercida de forma extremamente limitada, não se pode esperar resultados que gerem impacto econômico e social relevantes. Esse é um ponto que merece ser analisado com mais profundidade em pesquisas futuras, uma vez que os aspectos positivosdo spin-off só serão evidenciados com a difusão e comercialização das tecnologias e geração de emprego e renda. 
Por fim, cabe ressaltar que o conflito de tempo gerado em virtude do exercício das atividades empresariais e acadêmicas são dificultadores para que os pesquisadores criem empresas que possam gerar o desenvolvimento econômico pela atuação empreendedora. Isso talvez ajude a explicar por que apenas 11 dos 16 casos de spin-off identificados inicialmente nem ao menos chegaram na fase de comercialização do produto.

\section{Conclusão}

Tendo em vista os spin-offs são um fenômeno local, as Universidades devem de forma constante apresentar para pesquisadores quais são os caminhos e benefícios que eles poderão colher no futuro com a criação de spin-off. Vale lembrar que para os entrevistados as maiores motivações para empreender estavam relacionas a geração de impacto social e econômico por meio da difusão das tecnologias desenvolvidas dentro do laboratório.

Os dados colhidos deixam claro que a instituição analisada oferece mecanismos de suporte relevantes para que pesquisadores que tem interesse proteger as tecnologias, contudo, não há indícios apoio para a criação da empresa. Além disso, a fala dos entrevistados explicita que o tempo que necessário para desenvolver uma empresa de base tecnológica, com potencial para gerar lucro, vai muito além das oito horas semanais definida por meio de portaria interna da universidade e agora pelo novo Marco da Inovação.

Sendo assim, sugere-se que além de mais formação, os docentes envolvidos com a criação de spin-off possam ter a possibilidade de um enquadramento funcional diferenciado, de modo que seja possível conciliar as duas atividades. Até mesmo por que atividade empresarial tem potencial para gerar impactos positivos não só na carreira dos pesquisadores/professores, mas também na formação de recursos humanos. Este ponto foi evidenciado o levantamento de dados, os docentes envolvidos com as atividades empresariais têm um alto impacto de publicações e envolvem os alunos na criação das empresas.

A criação de spin-off acadêmicos, portanto pode ser um caminho relevante para formar alunos de graduação e pós-graduação, além representar uma possibilidade de geração de postos de trabalho para mestres e doutores.

Esta pesquisa contemplou apenas os casos de spin-off surgidos com a participação de pesquisadores/professores da instituição que optaram por explorar as tecnologias que foram patenteadas. O universo da amostra seria maior, caso a pesquisa levasse em consideração os spin-offs que nasceram sem a utilização de uma tecnologia resultante da proteção da propriedade intelectual por meio de patentes. Com essa mudança de padrão de pesquisa seria possível contemplar empresas de desenvolvimento de softwares dentre outras, que trabalham com segredo de mercado.

Em pesquisas futuras, sugere-se uma ampliação da pesquisa para outras instituições de ensino que também tenham vocação para a área de empreendedorismo acadêmico, para que se possa comparar este resultado com os de outras realidades, de modo que seja possível incluir não só pesquisadores, mas também outras partes envolvidas com o processo de criação de spin-off. 


\section{REFERÊNCIAS}

AMBOS, T. C. et al. When does university research get commercialized? Creating ambidexterity in research institutions. Journal of Management Studies, v. 45, n. 8, p. 14241447, 2008.

BERCOVITZ, J.; FELDMAN, M. Academic entrepreneurs: Organizational change at the individual level. Organization Science, v. 19, n. 1, p. 69-89, 2008.

CLARYSSE, B.; TARTARI, V.; SALTER, A. The impact of entrepreneurial capacity, experience and organizational support on academic entrepreneurship. Research Policy, v. 40, n. 8, p. 1084-1093, 2011.

COLYVAS, J. et al. How do university inventions get into practice? Management science, v. 48 , n. 1, p. 61-72, 2002 ..

CRESWELL, J.W. Projeto de pesquisa: métodos qualitativo, quantitativo e misto. 3. ed. Porto Alegre: Artmed: 2007.

DI GREGORIO, D.; SHANE, S. Why do some universities generate more start-ups than others? Research policy, v. 32, n. 2, p. 209-227, 2003.

ETZKOWITZ, H. et al. The future of the university and the university of the future: evolution of ivory tower to entrepreneurial paradigm. Research policy, v. 29, n. 2, p. 313330, 2000. ISSN 0048-7333.

FLICK, U. Uma introdução à pesquisa qualitativa. 2. ed. Porto Alegre: Artmed, 2004.

HAEUSSLER, C.; COLYVAS, J. A. Breaking the ivory tower: Academic entrepreneurship in the life sciences in UK and Germany. Research Policy, v. 40, n. 1, p. 41-54, 2011. ISSN 0048-7333.

HAYTER, C. S. In search of the profit-maximizing actor: Motivations and definitions of success from nascent academic entrepreneurs. The Journal of Technology Transfer, v. 36, n. 3, p. 340-352, 2011.

LOCKETT, A.; WRIGHT, M. Resources, capabilities, risk capital and the creation of university spin-out companies. Research policy, v. 34, n. 7, p. 1043-1057, 2005.

LUNDVALL, B.-Å. Innovation, growth, and social cohesion: the Danish model. Edward Elgar Publishing, 2002. .

MOSEY, S.; WRIGHT, M. From human capital to social capital: A longitudinal study of technology-based academic entrepreneurs. Entrepreneurship theory and practice, v. 31, n. 6, p. 909-935, 2007. 
NDONZUAU, F. N.; PIRNAY, F.; SURLEMONT, B. A stage model of academic spin-off creation. Technovation, v. 22, n. 5, p. 281-289, May 2002. ISSN 0166-4972. Disponível em: $<<$ Go to ISI $>$ ://WOS:000175533200002 >.

O'SHEA, R. P. et al. Delineating the anatomy of an entrepreneurial university: the Massachusetts Institute of Technology experience. R\&d Management, v. 37, n. 1, p. 1-16, 2007.

OWEN-SMITH, J.; POWELL, W. W. Careers and contradictions: Faculty responses to the transformation of knowledge and its uses in the life sciences. In: (Ed.). The transformation of work: Emerald Group Publishing Limited, 2001. p.109-140.

PHAN, P. H.; SIEGEL, D. S. The effectiveness of university technology transfer. Foundations and Trends ${ }^{\circledR}$ in Entrepreneurship, v. 2, n. 2, p. 77-144, 2006.

RASMUSSEN, E.; MOSEY, S.; WRIGHT, M. The influence of university departments on the evolution of entrepreneurial competencies in spin-off ventures. Research Policy, v. 43, n. 1, p. 92-106, 2014/02/01/ 2014. ISSN 0048-7333. Disponível em: < http://www.sciencedirect.com/science/article/pii/S004873331300111X >.

RAUEN, C. V. O Novo marco legal da inovação no Brasil: o que muda na relação ICTempresa?, 2016.

SHANE, S. Reflections on the 2010 AMR decade award: Delivering on the promise of entrepreneurship as a field of research. Academy of Management Review, v. 37, n. 1, p. 10$20,2012$.

SHANE, S.; VENKATARAMAN, S. The promise of entrepreneurship as a field of research. Academy of management review, v. 25, n. 1, p. 217-226, 2000. ISSN 0363-7425.

SHANE, S. A. Academic entrepreneurship: University spinoffs and wealth creation. Edward Elgar Publishing, 2004. ISBN 1843769824.

STUART, T. E.; DING, W. W. When do scientists become entrepreneurs? The social structural antecedents of commercial activity in the academic life sciences. American Journal of Sociology, v. 112, n. 1, p. 97-144, 2006.

VOHORA, A.; WRIGHT, M.; LOCKETT, A. Critical junctures in the development of university high-tech spinout companies. Research policy, v. 33, n. 1, p. 147-175, 2004. ISSN 0048-7333.

YIN, R.K. Estudo de caso: planejamento e métodos. 3. ed. Porto Alegre: Artmed, 2005 